\title{
Functional Diversity Metrics: How They Are Affected by Landscape Change and How They Represent Ecosystem Functioning in the Tropics
}

\author{
Jack H. Hatfield ${ }^{1}$ - Michelle L. K. Harrison ${ }^{1} \cdot$ Cristina Banks-Leite $^{1,2}$ (D) \\ Published online: 28 March 2018 \\ (C) The Author(s) 2018, corrected publication May/2018
}

\begin{abstract}
It is generally expected that landscape changes, such as habitat loss and fragmentation, should negatively affect functional diversity metrics, which in turn impact ecosystem functioning. In this review, we search for studies conducted in the tropics and published in the last 10 years to understand how different aspects of landscape change affect functional diversity metrics and how the latter are associated to ecosystem functioning. In total, we found 24 papers that assessed the effects of landscape metrics on functional diversity, evenness, divergence and composition, and although there was a general trend for functional diversity metrics to improve with habitat cover, we found a wide range of responses. Most surprisingly, however, we only found five studies from the tropics assessing the extent to which functional diversity metrics were correlated to measures of ecosystem functioning, and in general, very weak support was found. In conclusion, our results show that it is crucial to first investigate the level to which functional diversity metrics truly represent or may lead to changes in ecosystem functioning, and this is particularly important for animal communities in the tropics. Without such confirmation, there is little reason to pursue further work to reach a consensus regarding how landscape modification affects functional diversity metrics.
\end{abstract}

Keywords Ecosystem functioning $\cdot$ Ecosystem processes $\cdot$ Functional diversity $\cdot$ Functional traits $\cdot$ Tropics

\section{Introduction}

It is unambiguous that habitat loss and fragmentation are leading drivers of the global decline in terrestrial biodiversity [1]; however, their effects on ecosystem functioning are still debatable $[2 \bullet \bullet, 3]$. The impact of landscape alteration on ecosystem functioning has been commonly studied through the

Jack H. Hatfield and Michelle L. K. Harrisson would like to be recognised as first authors.

This article is part of the Topical Collection on Effects of Landscape Structure on Conservation of Species and Biodiversity

Electronic supplementary material The online version of this article (https://doi.org/10.1007/s40823-018-0032-x) contains supplementary material, which is available to authorized users.

Cristina Banks-Leite

c.banks@imperial.ac.uk

1 Department of Life Sciences, Imperial College London, Silwood Park Campus, Ascot SL5 7PY, UK

2 Department of Ecology, Biosciences Institute, Universidade de of São Paulo, São Paulo, SP 05508-090, Brazil prism of functional diversity metrics, as a step away from the simplicity of biodiversity and ecosystem functioning (BEF) approaches, towards the representation of functional traits within a community [4]. Such an approach, however, relies on the assumption that functional diversity metrics and ecosystem processes are strongly associated. Here we review the literature to assess how habitat changes affect functional diversity metrics, and we search for evidence of the extent to which functional trait diversity impacts ecosystem processes.

Functional diversity metrics are calculated by associating species-by-site matrices, such as presence-absence or abundance of species, to the species' functional traits; i.e. morphological or behavioural traits that are related to the role the species may perform in the ecosystem [5•]. Historically, the first metrics to be used in ecological studies were the richness of functional groups. However, since the seminal work of Petchey and Gaston [6], functional diversity went on to be measured with an approach similar to that employed for quantifying phylogenetic relatedness, and a wealth of new metrics to assess distinct components of diversity have been produced, such as functional evenness and divergence [7•]. Metrics based on functional traits are direct analogues of community metrics and, similarly to species diversity, functional diversity 
is the most commonly employed and supposedly the most powerful measure of variation in functional traits $[5 \cdot, 8]$.

The popularity of functional diversity metrics can be seen in the landscape ecology literature, where a number of studies have employed these measures to better understand how landscape change affects communities and ecosystems [9-11]. Observed changes to functional diversity metrics are interpreted as direct evidence that rates of ecosystem processes are also affected. Indeed, for temperate plants, there is enough evidence to suggest that functional diversity measures are highly correlated to rates of ecosystem processes (Fig. 1a) [13, 14]. However, ecosystem processes regulated by animals are often performed by more than one taxon $[2 \bullet \bullet$. For instance, pest predation may be performed by birds and spiders, and a reduction in the functional diversity of insectivorous birds may not affect pest regulation if the functional diversity of spiders increases (Fig. 1b). It is thus still unclear how changes in animal abundances, and their associated traits, affect ecosystem functions [15]. Furthermore, such overlap in functions performed by different animal taxa is likely to be more prominent in tropical ecosystems [16], suggesting that patterns observed for the temperate zones may not be applicable to the tropics. In the same way that hundreds of studies have assessed the links between biodiversity and ecosystem functions across a range of ecosystem (see [17] for a review), it is crucial that we fully understand whether functional diversity metrics can be indeed used as a proxy for ecosystem functioning.

Here, we reviewed the last 10 years of ecological literature to determine (1) how functional diversity metrics are affected by land cover and measures of landscape configuration and (2) how functional diversity metrics are related to rates of ecosystem processes and ecosystem functions. Our search was restricted to the tropics as they hold a large proportion of worldwide biodiversity [18], are at high risk from land use change [19, 20] and perform globally important ecosystem functions [21, 22]. We also focused only on terrestrial and riverine systems as landscape configuration is quantified in a different way for large aquatic systems due to its three-dimensional structure [23].

\section{Methods}

We searched the Web of Knowledge and Google Scholar for articles published between 2006 and 2016. Searches were conducted in December 2016 and January 2017. Google Scholar searches were continued until two pages in a row (20 records) contained no relevant results.

Published articles on the topic of landscape configuration and functional diversity metrics were selected based on the following search terms: 1. "functional diversity" AND tropic* AND ("patch size" OR "fragment size"), 2. "functional diversity" AND tropic* AND ("habitat connectivity" OR "landscape connectivity" OR "functional connectivity" OR a)

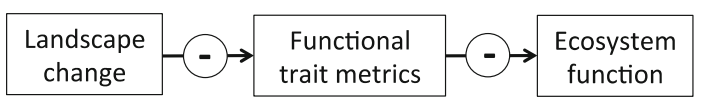

b)

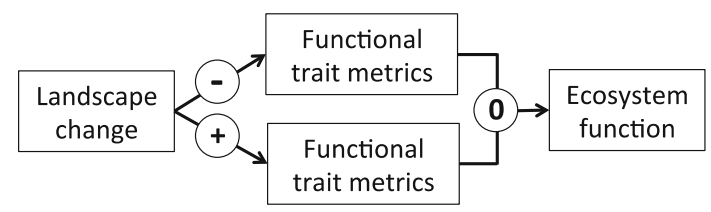

c)

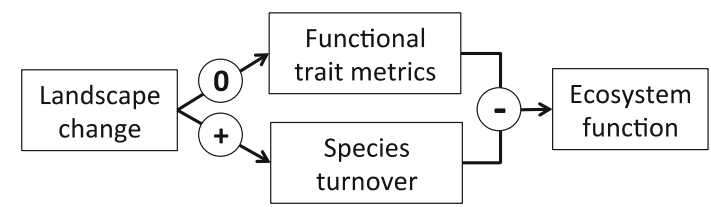

Fig. 1 Schematic representation of how landscape change may influence ecosystem functioning (EF) through changes in functional trait metrics. The current widespread expectation is that landscape changes negatively affect functional trait metrics, and in turn, the outcome on EF will also be negative (a). However, landscape changes may negatively affect some taxa while positively affect others, and the net result of these changes onto EF is neutral (b). See Ewers et al. [2••] for an example of $\mathbf{b}$. Furthermore, landscape changes may not affect functional trait metrics, such as functional diversity, but affect other community metrics such as species turnover, or species specialisation. The net result of these changes will be a negative impact of ecosystem function. See de Coster et al. [12••] and text for an example of $\mathbf{c}$

"structural connectivity"), 3. "functional diversity" AND tropic* AND "habitat loss" AND fragment*. Studies were restricted to those that were (1) conducted in the tropics and (2) examined a gradient of landscape fragmentation and (3) made a quantitative assessment of functional diversity.

Similarly, we conducted two searches to find published articles about functional diversity metrics and ecosystem functions using the following set of terms: 1 . "functional diversity" AND tropic* AND ("ecosystem service" OR "ecosystem process" OR "ecosystem function"), 2. "functional diversity" AND tropic* AND ("pollination" OR "insectivor"” OR "seed dispersal" OR "decomposition" OR "carbon stocks" OR "nitrogen"). These specific terms were chosen to reflect the primary functions performed by vertebrates, invertebrates and plants within tropical ecosystems.

\section{Results}

\section{Functional Diversity Metrics and Landscape Configuration}

In total, we found 24 published articles that investigate the effects of land cover and landscape configuration on different functional diversity metrics (Table 1; Table S1). A range of taxa were studied incorporating plants, invertebrates and vertebrates but the number of habitat types was limited, with most studies 
Table 1 Table summarising the results of referenced studies comparing functional diversity metrics to landscape metrics

\begin{tabular}{|c|c|c|c|c|c|}
\hline Functional metric & Fragmented vs. reference & Edge effects & Patch size & Habitat percentage & Connectivity \\
\hline Diversity/richness & $\begin{array}{l}+[24-27] \\
\mathbf{0}[28,29]\end{array}$ & $\begin{array}{l}+[24,30] \\
\mathbf{0}[11,31]\end{array}$ & $\begin{array}{l}+[9,28,32,33] \\
\mathbf{0}[11,34] \\
\sim[29]\end{array}$ & $\begin{array}{l}+[35,36] \\
0[12 \bullet \bullet] \\
-[37]\end{array}$ & $+[35]$ \\
\hline Evenness & $\begin{array}{l}+[25] \\
\mathbf{0}[28]\end{array}$ & $\begin{array}{l}+[11] \\
\mathbf{0}[31]\end{array}$ & $\begin{array}{l}\mathbf{0}[28] \\
\sim[10] \\
-[11]\end{array}$ & $\begin{array}{l}+[36] \\
0[36,37] \\
-[12 \bullet \bullet]\end{array}$ & \\
\hline Divergence/dispersion & $\begin{array}{l}+[25,38] \\
\mathbf{0}[28]\end{array}$ & $\begin{array}{l}+[39] \\
0[11,31]\end{array}$ & $\begin{array}{l}\mathbf{0}[28] \\
-[11,39]\end{array}$ & $\begin{array}{l}\mathbf{0}[36] \\
-[37,40,41]\end{array}$ & $-[39]$ \\
\hline Integrity/composition & $\sim[42]$ & & & $+[12 \bullet \bullet]$ & \\
\hline Similarity (functional $\beta$-diversity) & $-[43]$ & $-[43]$ & & & \\
\hline
\end{tabular}

The directionality of relationship is given in bold. A positive correlation indicates higher functional diversity in increasingly intact habitat. Categorisation of functional metrics was largely based on Mouchet et al. [7•]

+ positive correlation, 0 no clear correlation detected, - negative correlation, $\sim$ non-linear or unstated relationship

focusing on forest systems. Geographically, the majority of studies concentrated on the Brazilian Atlantic and Amazon forests, with nearly all studies focusing on Central and South America. Landscape configuration was assessed in a number of ways. The simplest method was the comparison of fragmented or edge habitat to its equivalent continuous or pristine reference site. Other studies looked at individual landscape metrics such as patch size, patch shape, connectivity and percentage of focal habitat. We summarise the different approaches used in five main categories: (1) comparisons between continuous and fragmented habitat, (2) edge effects, (3) patch size, (4) percentage habitat cover and (5) connectivity (Table 1).

Overall habitat loss and fragmentation reduced functional diversity, but there were some exceptions and the nature of the change showed considerable variation. Many studies also compared the responses of species richness to habitat loss and fragmentation, and these responses were mostly in agreement with those observed by functional response metrics (Table S2). Because of the large variation in taxa, biome, functional and landscape metrics used, the evidence (or lack thereof) to support the existence of a relationship between functional metrics and landscape metrics was usually obtained from one or few studies.

(1) Fragments vs. continuous forest: The majority of studies detected an increase in functional diversity in continuous habitat in comparison with fragmented [24-27, 38] (Table 1). Pollination syndromes were more diverse in continuous forest than in fragments [24, 27], and tree seedling assemblages also differed in functional composition between small forest fragments and sites in mature forest [42]. Even when compared to naturally fragmented forest, continuous forest was found to have higher functional richness, evenness and divergence in plant communities [25]. Continuous forests were found to harbour higher functional richness of mammals than riparian fragments [26]. In their pan-tropical study of mammal communities, Ahumada et al. [38] also found that functional dispersion was higher in continuous forest when compared to fragments. However, this pattern did not hold for other taxa-no differences in functional richness, evenness or dispersion were observed when comparing dung beetle communities between fragments and continuous forest [28] or when assessing the variation in functional richness of Atlantic Forest avian communities between mature forest and regenerating fragments [29]. While the majority of studies focused on functional measures analogous to $\alpha$-diversity, Sfair et al. [43] examined functional $\beta$-diversity in plants. They found it to be higher in fragments than old growth forest and highest at fragment edges [43]. This indicates that functional diversity exhibits greater heterogeneity in fragments (especially edges) as opposed to continuous forest, but patterns were less clear when considering only species occurrence as opposed to abundance [43].

(2) Edge effects: The altered abiotic conditions in edge habitats [44] can have substantial effects upon community and ecosystem processes [45, 46], and edge effects may even be the cause of many observed area effects [47]. Despite such pervasive impacts, we could not find a consensus regarding their effects on functional diversity metrics (Table 1). The functional evenness of tree communities and diversity of their pollination syndromes were reported to be higher in fragment interiors than edges [11, 27]; however, no changes in richness or divergence were found [11]. No differences were found for forest herpetofauna in forest-oil palm systems when functional richness, evenness and divergence were considered [31]. Overall this suggests that the effect of edges on functional diversity is less clear than the overall effects of fragmentation. Assessing the impacts of patch shape is another approach to understanding the importance of edge effects. This is because as patch shape becomes increasingly irregular, the amount of edge 
habitat relative to area increases. Patch shape was considered in only two studies, both of which found that more compact patches supported communities with a more diverse array of functions, with higher functional diversity [30] and divergence [39].

(3) Patch size: A positive relationship between patch size and functional richness was found for copro-necrophagous beetles [28], mammals [9], trees [32] and vertebrates [33]. Nonetheless, these results did not hold for all plant communities [11] or birds [34], in which functional richness was found to vary independently of patch size. Similarly, no effects of patch size were found on functional evenness or divergence of beetle assemblages [28]. In contrast, a negative correlation was reported for patch size and functional divergence in phyllostomid bats [39] and trees [11]. More complex patterns have been observed, such as a non-linear relationship with patch size [29].

(4) Habitat amount: Mammal functional richness was positively correlated with forest cover [35], as was avian functional richness in agricultural and arable landscapes [36]. For bird species in forest fragments, no link between functional richness and forest cover was found and evenness decreased with increasing forest cover; however, functional integrity (similarity to control sites) increased with forest cover [12••]. This suggests a change in species' functional traits, producing a new functional space that is no less diverse. The functional richness and dispersion of riverine fish communities decreased with increasing forest cover, but evenness remained unaffected and the findings differed dependent on local habitat type [37]. In contrast, some research indicates that the nearest taxon index is negatively associated with forest cover, suggesting forested streams have more functionally complementary fish communities [40]. For trees, a negative correlation was found between functional divergence and natural vegetation cover [41]. These conflicting results may suggest a shift between two communities, both of which are functionally diverse yet distinct. The effect of habitat cover is also highly dependent on scale [48] and the results may be affected heavily by the gradient examined.

(5) Connectivity: Compared with previous landscape metrics, few studies explicitly examined connectivity. Mammal functional richness was found to correlate positively with connectivity [35], whereas work on bats indicates that their functional divergence decreased as proximity to other patches increased [39].

\section{Functional Diversity Metrics and Ecosystem Functioning}

We found only five studies published in the last 10 years that quantified functional diversity metrics alongside an independent measure of ecosystem processes in tropical systems. Only two taxa were assessed (birds and plants) and only four functions were measured (seed dispersal, pest control, aboveground biomass and carbon storage). The overall result is that although functional diversity metrics are somehow correlated with ecosystem processes, functional diversity per se is not a good predictor of ecosystem functioning. However, with only five studies, we are unable to draw any firm conclusions or provide any meaningful insight.

Bird functional diversity metrics were shown to be weakly correlated with the provisioning of pest control, but may provide a better proxy for seed dispersal. A meta-analysis of nine avian exclusion studies in tropical coffee and cacao agroforests compared the predictive power of species richness and functional diversity metrics in determining arthropod predation [49]. Functional richness exhibited a higher degree of correlation with arthropod predation when the metric included multiple traits, highlighting the importance of trait selection when using measures of functional diversity. However, functional group richness was a better predictor of ecosystem functioning than functional diversity metrics, and most importantly, species richness provided the strongest predictive power of all the metrics. Another study investigated how functional diversity related to frugivorous birds' activity and seed dispersal in different habitats [50]. The proportion of interactions between frugivorous birds and fruit was two times greater in edge habitat than within the forest interior. Functional richness was greater at the forest edge and correlated with the higher number of fruit-bird interactions. Variation in functional richness between the two habitat types was also associated with changes in plant species diversity. However, this study did not include any other measure of seed dispersal, such as seed rain or seed viability; thus, it remains to be confirmed whether greater functional richness of birds does indeed lead to increases in seed dispersal.

In plants, functional dominance has been shown to be a better proxy for carbon storage than functional richness. The role of functional diversity metrics as a determinant of carbon storage was investigated in natural tropical forest in Panama [51]. Functional dominance accounted for most of the variation in carbon storage in natural forest sites. A broader study, encompassing natural tropical forest sites across Africa, Asia and the Americas, reported similar findings [52]. The carbon storage capacity of 11 tropical forests was most strongly correlated with increased functional dominance and taxonomic diversity, but not with functional diversity. However, the study results suggest that the suitability of plant functional diversity indices to predict carbon storage capacity may vary depending on forest type [52]. In a similar study of three neo-tropical forests, aboveground biomass was found to correlate positively with key individual plant functional traits, most significantly with wood specific gravity and maximum adult height. In contrast, there was no relationship between aboveground 
biomass and functional variety as measured by functional richness, evenness, dispersion and divergence [53].

\section{Discussion}

It has been generally expected that habitat loss and fragmentation have detrimental effects on functional diversity metrics, which in turn will negatively affect ecosystem functioning (Fig. 1a). Based on current empirical evidence, our results indicate that only some of these expectations are warranted for tropical landscapes. Although the majority of studies reported higher functional diversity or richness in more pristine habitats (Table 1), there was little consensus among studies that investigated additional functional diversity and landscape metrics. There is an even greater lack of clarity regarding the interplay between functional metrics and ecosystem functions, as only five studies with contradictory results were found.

A number of potential issues could be underlying such unmet expectations. It is possible that functional metric patterns are more complex than originally thought due to the idiosyncrasies of individual taxa-bats, for example, often show conflicting patterns when compared to other taxa. There may also be geographic differences, with abiotic and biotic factors unique to a particular site or region, exerting a strong influence on the nature of functional changes. The role of temporal and site-specific differences is starting to be recognised when comparing sensitivity (or response) traits to landscape change [54-56], and the situation may be similar for functional traits, making generalisation difficult.

Trait choice is of extreme importance for analyses using functional metrics as the inclusion of traits unrepresentative of function, or the exclusion of traits that are functionally important, can both influence the validity of the results $[6$, 57]. Notwithstanding, studies on similar taxonomic groups most commonly differ in their trait selection [35, 38]. On the other hand, many studies still focus on species richness of functional groups. This is a coarse measure of functional diversity, which is impervious to within-group variation, and has been found to explain less variation in ecosystem functioning than more complex metrics [57].

Finally, the effects of habitat fragmentation are highly context dependent [58]. The intervening matrix and amount of habitat cover in the region can modify how species respond to patch size and isolation, making it difficult to obtain clear patterns even for simpler metrics such as species abundance and species richness $[59,60]$. And in the same way that habitat fragmentation can improve some community metrics (such as beta-diversity), it may also have positive consequences for some functional metrics. For example, Magnago et al. [11] found functional divergence to decrease with increasing patch size, whereas the majority of authors found an increase with patch size $[9,28,32,33]$. There are a number of reasons why these results may have been generated. Fragmented landscapes may provide a wider range of habitat types and hence niches - therefore, they may have less niche homogenisation [11] and contain a community with a more diverse array of traits [39]. Heterogeneous landscapes may support a wider range of species, hence occupying a greater area in trait space. Nonetheless, an increase in functional divergence in fragmented habitats does not necessarily mean that the functions are similar to those performed in pristine habitats and does not mean that ecosystem functioning will be positively impacted.

We were surprised, however, to find such weak evidence supporting the view that functional metrics are correlated to ecosystem functioning or ecosystem dynamics. Not only did we find just five studies, but they failed to show overwhelming support for the use of functional diversity metrics as a proxy of ecosystem functioning. Even species richness, which is a notoriously poor community metric [60-62], was found to be better than functional richness in predicting the performance of some ecosystem functions. Further research is vital in establishing the link between functional diversity metrics and ecosystem functioning, and there are at least two reasons why this link may not be strong. Firstly, functional metrics are usually only measured from the perspective of one taxon. Such a modular view of ecosystem dynamics likely fails to assess distinct groups that often perform similar functions, and which may show contrasting responses to habitat change (Fig. 1b). A prime example of this occurs in Borneo, where ecosystem functions are maintained across a gradient of habitat disturbance, despite marked declines in key species [2••]. In human-modified habitat, invertebrate groups, such as termites, ants, beetles and earthworms, decrease in abundance $[2 \bullet \bullet]$. However, decomposition, seed consumption and invertebrate predation are still performed at the same rates, as vertebrates take up the lead role in those functional groups [2••]. Had these authors only focused on functional diversity of invertebrates, they would have reported a strong decrease in ecosystem functioning. Secondly, there may be situations where functional richness does not vary, but ecosystem functioning is impacted (Fig. 1c). For instance, functional richness of birds in the Atlantic Forest of Brazil does not vary meaningfully, but dietary specialisation is significantly reduced by habitat loss [12••]. Specialist insectivores are believed to have a stronger impact on insect populations than generalist insectivores [63]; thus, potentially, the strength of arthropod control is diminished in more deforested sites despite absence of variation in functional richness.

\section{Conclusions}

Due to the small sample of published articles yielded by the literature search, it is impossible to draw any firm conclusions 
about the performance and suitability of functional diversity metrics in predicting ecosystem function in tropical landscapes, and this is particularly important for animal taxa. Although a larger pool of studies have been conducted on the effects of landscape change on functional metrics, the picture remains unclear due to the abundance of contrasting results. Although species diversity and functional diversity are clearly correlated (Table S2), the link between functional diversity metrics and landscape change may itself be irrelevant. Unless the association between functional metrics and ecosystem functioning is clearly established, it is more likely that functional diversity is related to ecosystem functioning through a BEF relationship. To fully comprehend which functions species perform within tropical ecosystems, and how this fluctuates with landscape change and configuration, we suggest that further research is needed to establish the connection between landscape changes, functional traits and ecosystem functioning. If these potentially powerful tools are found to be a good proxy for important ecosystem services, the employment of these methods in conservation planning and strategy could be invaluable.

Funding Information Funding was provided by NERC grant NE/ K016393/1 to C.B.L and J.H.H and NERC PhD studentship to M.L.K.H. This paper represents a contribution to the Grand Challenges in the Ecosystem and Environment Initiative of Imperial College.

\section{Compliance with Ethical Standards}

Conflict of Interest On behalf of all authors, the corresponding author states that there is no conflict of interest.

Human and Animal Rights and Informed Consent Article does not contain studies on animals performed by the authors.

Open Access This article is distributed under the terms of the Creative Commons Attribution 4.0 International License (http:// creativecommons.org/licenses/by/4.0/), which permits unrestricted use, distribution, and reproduction in any medium, provided you give appropriate credit to the original author(s) and the source, provide a link to the Creative Commons license, and indicate if changes were made.

\section{References}

Papers of particular interest, published recently, have been highlighted as:

- Of importance

•- Of major importance

1. Newbold T, Hudson LN, Hill SLL, Contu S, Lysenko I, Senior RA, et al. Global effects of land use on local terrestrial biodiversity. Nature. 2015;520:45-50.

2.• Ewers RM, Boyle MJW, Gleave RA, Plowman NS, Benedick S, Bernard $\mathrm{H}$, et al. Logging cuts the functional importance of invertebrates in tropical rainforest. Nat Commun. 2015;6:6836. This article demonstrates the importance of considering multiple taxa when examining functional diversity.

3. Hooper DU, Chapin FS, Ewel JJ, Hector A, Inchausti P, Lavorel S, et al. Effects of biodiversity on ecosystem functioning: a consensus of current knowledge. Ecol Monogr. 2005;75:3-35.

4. Reiss J, Bridle JR, Montoya JM, Woodward G. Emerging horizons in biodiversity and ecosystem functioning research. Trends Ecol Evol. 2009;24:505-14.

5. Petchey OL, Gaston KJ. Functional diversity: back to basics and looking forward. Ecol Lett. 2006;9:741-58. This article introduces the concept of functional diversity.

6. Petchey OL, Gaston KJ. Functional diversity (FD), species richness and community composition. Ecol Lett. 2002;5:402-11.

7. Mouchet MA, Villéger S, Mason NWH, Mouillot D. Functional diversity measures: an overview of their redundancy and their ability to discriminate community assembly rules. Funct Ecol. 2010;24: $867-76$. This article provides an overview of functional diversity metrics.

8. Hoehn P, Tscharntke T, Tylianakis JM, Steffan-Dewenter I. Functional group diversity of bee pollinators increases crop yield. Proc R Soc B Biol Sci. 2008;275:2283-91.

9. Magioli M, Ribeiro MC, Ferraz KMPMB, Rodrigues MG. Thresholds in the relationship between functional diversity and patch size for mammals in the Brazilian Atlantic Forest. Anim Conserv. 2015; 18:499-511.

10. Leal IR, Filgueiras BKC, Gomes JP, Iannuzzi L, Andersen AN. Effects of habitat fragmentation on ant richness and functional composition in Brazilian Atlantic forest. Biodivers Conserv. 2012;21: 1687-701.

11. Magnago LFS, Edwards DP, Edwards FA, Magrach A, Martins SV, Laurance WF. Functional attributes change but functional richness is unchanged after fragmentation of Brazilian Atlantic forests. J Ecol. 2014;102:475-85.

12.• De Coster G, Banks-Leite C, Metzger JP. Atlantic forest bird communities provide different but not fewer functions after habitat loss. Proc R Soc B Biol Sci. 2015;282:20142844. This article provides an example of how landscape changes may not alter functional diversity and still impact ecosystem functioning.

13. Tilman D, Knops J, Wedin D, Reich P, Ritchie M, Siemann E. The influence of functional diversity and composition on ecosystem processes. Science. 1997;277:1300-2.

14. Díaz S, Cabido M. Vive la différence: plant functional diversity matters to ecosystem processes. Trends Ecol Evol. 2001;16:64655 .

15. de Bello F, Lavorel S, Díaz S, Harrington R, Cornelissen JHC, Bardgett RD, et al. Towards an assessment of multiple ecosystem processes and services via functional traits. Biodivers Conserv. 2010;19:2873-93.

16. Klopfer PH, MacArthur RH. On the causes of tropical species diversity: niche overlap. Am Nat. 1961;95:223-6.

17. Hooper DU, Adair EC, Cardinale BJ, Byrnes JEK, Hungate BA, Matulich KL, et al. A global synthesis reveals biodiversity loss as a major driver of ecosystem change. Nature. 2012;486:105.

18. Myers N, Mittermeier RA, Mittermeier CG, da Fonseca GAB, Kent J. Biodiversity hotspots for conservation priorities. Nature. 2000;403:853-8.

19. Hansen MC, Stehman SV, Potapov PV, Loveland TR, Townshend JRG, DeFries RS, et al. Humid tropical forest clearing from 2000 to 2005 quantified by using multitemporal and multiresolution remotely sensed data. Proc Natl Acad Sci. 2008;105:9439-44.

20. Sala OE, Stuart Chapin F III, Armesto JJ, Berlow E, Bloomfield J, et al. Global biodiversity scenarios for the year 2100 . Science. 2000:287.

21. Steffan-Dewenter I, Kessler M, Barkmann J, Bos MM, Buchori D, Erasmi S, et al. Tradeoffs between income, biodiversity, and 
ecosystem functioning during tropical rainforest conversion and agroforestry intensification. Proc Natl Acad Sci. 2007;104:4973-8.

22. Foley JA, DeFries R, Asner GP, Barford C, Bonan G, Carpenter SR, et al. Global consequences of land use. Science. 2005;309:570.

23. Wedding LM, Christopher LA, Pittman SJ, Friedlander AM, Jorgensen S. Quantifying seascape structure: extending terrestrial spatial pattern metrics to the marine realm. Mar Ecol Prog Ser. 2011;427:219-32.

24. Girão LC, Lopes AAV, Tabarelli M, Bruna EM, Mayfield M, Boni $\mathrm{M}$, et al. Changes in tree reproductive traits reduce functional diversity in a fragmented Atlantic forest landscape. PLoS One. 2007;2:e908.

25. Munguía-Rosas MA, Jurado-Dzib SG, Mezeta-Cob CR, Montiel S, Rojas A, Pech-Canché JM. Continuous forest has greater taxonomic, functional and phylogenetic plant diversity than an adjacent naturally fragmented forest. J Trop Ecol. 2014;30:323-33.

26. Zimbres B, Peres CA, Machado RB. Terrestrial mammal responses to habitat structure and quality of remnant riparian forests in an Amazonian cattle-ranching landscape. Biol Conserv. 2016;206: 283-92.

27. Lopes AV, Girão LC, Santos BA, Peres CA, Tabarelli M. Long-term erosion of tree reproductive trait diversity in edge-dominated Atlantic forest fragments. Biol Conserv. 2009;142:1154-65.

28. Barragán F, Moreno CE, Escobar F, Halffter G, Navarrete D, Chapin F, et al. Negative impacts of human land use on dung beetle functional diversity. PLoS One. 2011;6:e17976.

29. Dias DFC, Ribeiro MC, Felber YT, Cintra ALP, de Souza NS, Hasui É. Beauty before age: landscape factors influence bird functional diversity in naturally regenerating fragments, but regeneration age does not. Restor Ecol. 2016;24:259-70

30. Arellano-Rivas A, De-Nova JA, Munguía-Roses MA. Patch isolation and shape predict plant functional diversity in a naturally fragmented forest. J Plant Ecol. 2016;52:1-36.

31. Gallmetzer N, Schulze CH. Impact of oil palm agriculture on understory amphibians and reptiles: a Mesoamerican perspective. Glob Ecol Conserv. 2015;4:95-109.

32. Benchimol M, Peres CA. Edge-mediated compositional and functional decay of tree assemblages in Amazonian forest islands after 26 years of isolation. J Ecol. 2015;103:408-20.

33. Benchimol M, Peres CA. Widespread forest vertebrate extinctions induced by a mega hydroelectric dam in lowland Amazonia. PLoS One. 2015;10:e129818.

34. Ulrich W, Lens L, Tobias JA, Habel JC. Contrasting patterns of species richness and functional diversity in bird communities of east African cloud forest fragments. PLoS One. 2016;11:e163338.

35. Magioli M, Ferraz KMPM d B, Setz EZF, Percequillo AR, Rondon MV d SS, Kuhnen VV, et al. Connectivity maintain mammal assemblages functional diversity within agricultural and fragmented landscapes. Eur J Wildl Res. 2016;62:431-46.

36. Prescott GW, Gilroy JJ, Haugaasen T, Medina Uribe CA, Foster WA, Edwards DP. Reducing the impacts of Neotropical oil palm development on functional diversity. Biol Conserv. 2016;197:13945.

37. Teresa FB, Casatti L. Influence of forest cover and mesohabitat types on functional and taxonomic diversity of fish communities in Neotropical lowland streams. Ecol Freshw Fish. 2012;21:43342.

38. Ahumada JA, Silva CEF, Gajapersad K, Hallam C, Hurtado J, Martin E, et al. Community structure and diversity of tropical forest mammals: data from a global camera trap network. Philos Trans R Soc Lond Ser B Biol Sci. 2011;366:2703-11.

39. Cisneros LM, Fagan ME, Willig MR. Effects of human-modified landscapes on taxonomic, functional and phylogenetic dimensions of bat biodiversity. Divers Distrib. 2015;21:523-33.
40. Bordignon CR, Casatti L, Pérez-Mayorga MA, Teresa FB, Brejão GL. Fish complementarity is associated to forests in Amazonian streams. Neotrop Ichthyol. 2015;13:579-90.

41. Mendes G, Arroyo-Rodríguez V, Almeida WR, Pinto SRR, Pillar VD, Tabarelli M. Plant trait distribution and the spatial reorganization of tree assemblages in a fragmented tropical forest landscape. Plant Ecol. 2016;217:31-42.

42. Santo-Silva EE, Almeida WR, Melo FPL, Zickel CS, Tabarelli M. The nature of seedling assemblages in a fragmented tropical landscape: implications for forest regeneration. Biotropica. 2013;45: 386-94.

43. Sfair JC, Arroyo-Rodriguez V, Santos BA, Tabarelli M. Taxonomic and functional divergence of tree assemblages in a fragmented tropical forest. Ecol Appl. 2016;26:1816-26.

44. Ewers RM, Banks-Leite C. Fragmentation impairs the microclimate buffering effect of tropical forests. PLoS One. 2013;8:e58093.

45. Laurance WF, Lovejoy TE, Vasconcelos HL, Bruna EM, Didham RK, Stouffer PC, et al. Ecosystem decay of Amazonian forest fragments: a 22-year investigation. Conserv Biol. 2002;16:605-18.

46. Neate-Clegg MHC, Morshuis EC, Banks-Leite C. Edge effects in the avifaunal community of riparian rain-forest tracts in Tropical North Queensland. J Trop Ecol. 2016;32:280-9.

47. Banks-Leite C, Ewers RM, Metzger J-P. Edge effects as the principal cause of area effects on birds in fragmented secondary forest. Oikos. 2010;119:918-26.

48. Banks-Leite C, Ewers RM, Metzger JP. The confounded effects of habitat disturbance at the local, patch and landscape scale on understorey birds of the Atlantic Forest: implications for the development of landscape-based indicators. Ecol Indic. 2013;31:82-8.

49. Philpott SM, Soong O, Lowenstein JH, Luz Pulido A, Lopez DT, Flynn DFB, et al. Functional richness and ecosystem services: bird predation on arthropods in tropical agroecosystems. Ecol Appl. 2009; 19:1858-67.

50. Saavedra F, Hensen I, Beck SG, Böhning-Gaese K, Lippok D, Töpfer T, et al. Functional importance of avian seed dispersers changes in response to human-induced forest edges in tropical seed-dispersal networks. Oecologia. 2014;176:837-48.

51. Ruiz-Jaen MC, Potvin C. Can we predict carbon stocks in tropical ecosystems from tree diversity? Comparing species and functional diversity in a plantation and a natural forest. New Phytol. 2011;189: 978-87.

52. Cavanaugh KC, Gosnell JS, Davis SL, Ahumada J, Boundja P, Clark DB, et al. Carbon storage in tropical forests correlates with taxonomic diversity and functional dominance on a global scale. Glob Ecol Biogeogr. 2014;23:563-73.

53. Finegan B, Peña-Claros M, de Oliveira A, Ascarrunz N, Bret-Harte MS, Carreño-Rocabado G, et al. Does functional trait diversity predict above-ground biomass and productivity of tropical forests? Testing three alternative hypotheses. J Ecol. 2015;103:191-201.

54. Thornton D, Branch L, Sunquist M. Passive sampling effects and landscape location alter associations between species traits and response to fragmentation. Ecol Appl. 2011;21:817-29.

55. Vetter D, Hansbauer MM, Végvári Z, Storch I. Predictors of forest fragmentation sensitivity in Neotropical vertebrates: a quantitative review. Ecography (Cop). 2011;34:1-8.

56. Hatfield JH, Orme CDL, Tobias JA, Banks-Leite C. Trait-based indicators of bird species sensitivity to habitat loss are effective within but not across data sets. Ecol Appl. 2018;28:28-34.

57. Petchey OL, Hector A, Gaston KJ. How do different measures of functional diversity perform? Ecology. 2004;85:847-57.

58. Banks-Leite C, Ewers RM, Pimentel RG, Metzger JP. Decisions on temporal sampling protocol influence the detection of ecological patterns. Biotropica. 2012;44:378-85.

59. Prugh LR, Hodges KE, Sinclair ARE, Brashares JS. Effect of habitat area and isolation on fragmented animal populations. Proc Natl Acad Sci. 2008;105:20770-5. 
60. Banks-Leite C, Ewers RM, Metzger JP. Unraveling the drivers of community dissimilarity and species extinction in fragmented landscapes. Ecology. 2012;93:2560-9.

61. Banks-Leite C, Pardini R, Boscolo D, Cassano CR, Puettker T, Barros CS, et al. Assessing the utility of statistical adjustments for imperfect detection in tropical conservation science. J Appl Ecol. 2014;51:849-59.
62. Barlow J, Gardner TA, Araujo IS, Avila-Pires TC, Bonaldo AB, Costa JE, et al. Quantifying the biodiversity value of tropical primary, secondary, and plantation forests. Proc Natl Acad Sci. 2007;104:18555-60.

63. Clavel J, Julliard R, Devictor V. Worldwide decline of specialist species: toward a global functional homogenization? Front Ecol Environ. 2011;9:222-8. 